\title{
RECURSOS LINGÜÍSTICOS EN LA TITULACIÓN PERIODÍSTICA COSTARRICENSE: EL CASO DE LA NACIÓN Y EL DIARIO LA EXTRA
}

\author{
Dorde Cuvardic García \\ Ericka Vargas Castro
}

\begin{abstract}
RESUMEN
En el presente artículo, se analizan las estrategias lingüísticas utilizadas en la conformación de titulares por dos de los periódicos con mayor trascendencia en el ámbito costarricense: $L a$ Extra, principal informativo sensacionalista y La Nación, principal informativo de referencia dominante. Se estudian procedimientos morfológicos, sintácticos y semánticos, así como la sufijación, prefijación, siglación, tropos (metáfora, alegoría, sinécdoque, metonimia), acortamiento, expresiones hechas, estilo directo y diversas modalidades de estilo indirecto (del discurso reproducido de las fuentes), la elisión del agente y del auxiliar de las construcciones pasivas o el uso del nosotros inclusivo. Se concluye que los principales condicionantes productivos que intervienen en la titulación son de corte ideológico y estilístico; por ello, predominan técnicas asociadas con la economía del lenguaje. La necesidad de concisión y de incidir fáticamente en los lectores interviene en la estructura sintáctica y el léxico seleccionado. En La Extra se utilizan procedimientos típicos de la titulación de los diarios sensacionalistas de otros países latinoamericanos, como el uso de léxico popular, mientras que La Nación presenta diferencias respecto de la titulación de otros periódicos de referencia dominante, tal como la escasa presencia de procesos de nominalización. Palabras clave: medios impresos, titulación periodística, La Nación, La Extra, recursos lingüísticos, análisis del discurso.
\end{abstract}

\begin{abstract}
The following article analyses the linguistic strategies involved in the headings' writing process used by two of the most important Costa Rican newspapers: La Extra, main sensationalist journal, and La Nación, main dominant reference diary. Morphological, syntactic, and semantic mechanisms will be analyzed, along with other aspects such as suffixation, prefixation, initials, tropes (metaphor, allegory, synecdoche, metonymy), shortenings, idioms, direct and indirect style -of the reproduced speech source-, agent and passive auxiliary elision, and the use of the inclusive "we". The conclusion points out that headings' linguistic form tends to be prompted by ideological and stylistic factors; therefore, techniques focused on language economy predominate. The pursue of concision and phatic influence on readers motivates the syntactic structure and chosen vocabulary. In La Extra, the mechanisms used in the headlines' conformation are similar to those sensationalist procedures taken into account in other Latin American countries -such as slang preference-, while La Nación shows some differences compared to other newspapers of dominant reference -like the low presence of nominalization processes.
\end{abstract}

Key words: Printed Media, Newspaper Headings, La Nación, La Extra, Linguistics Strategies, Discuorse Analysis.

Dr. Dorde Cuvardic García. Profesor de la Escuela de Filología, Lingüística y Literatura. Universidad de Costa Rica. Correo electrónico: dcuvardic@yahoo.es

Bach. Ericka Vargas Castro. Egresada de Maestría en Lingüística. Profesora. Instituto Tecnológico de Costa Rica. Correo electrónico: vacaer@yahoo.com

Recepción: 11- 01- 2010

Aceptación: 13- 02- 2010 


\section{Introducción: presentación del tema, justificación y objetivos}

La opinión popular propone que el periodismo es una ventana al mundo. Los propios medios han contribuido a apuntalar este enunciado, que pertenece al radio de acción del llamado sentido común ("los hechos como son"). Pero frente a esta visión ingenua de la práctica periodística hay que destacar, por el contrario, su carácter ideológico. Los medios no presentan la realidad, sino que la construyen discursivamente. Martini (2000: 24) afirma que “el periodista no sólo 'escribe' sino que “construye la información””. Del anterior enunciado se puede deducir que en un primer momento se produce un evento real. Aparece, entonces, la necesidad de representarlo discursivamente. Aquí hacen acto de presencia múltiples factores como son la fidelidad de las fuentes o los fines ideológicos que se tengan a la hora de redactar la noticia. Aparece así el proceso de construcción de la noticia. La ideología y la estructura organizativa del medio brindarán un acercamiento específico al acontecimiento y le otorgarán ciertos significados.

Espacio paradigmático de esta representación discursiva es el titular. Hernando (2000: 17) distingue tres componentes primordiales en la noticia: el titular, la entrada y el cuerpo. Según este autor, "Lo más importante del titular es [...] el título”. No se trata de una tautología. Debe recordarse que la titulación informativa consta de volanta (arriba del titular, sobre antecedentes e información contextual de la acción principal), titular propiamente dicho (actores y acciones principales) y bajada (acciones y actores secundarios). El titular se encuentra destacado tipográficamente del resto de la noticia y en él se encuentran condensados los significados que se desean transmitir. Por otra parte, la entrada o lead es el párrafo inicial y contiene lo sustancial de la noticia (¿cuándo?, ¿cómo?, ¿dónde?, ¿por qué?), mientras que los demás párrafos forman el cuerpo, que contiene el resto de los detalles del acontecimiento. La información se va dando en un orden decreciente de importancia, debido a que, ante la necesidad de eliminar algunos párrafos por falta de espacio, se pueden descartar aquellos que se encuentren al final. En estas circunstancias, su ausencia no afectaría el contenido global.

De acuerdo con este orden de prioridades discursivas, está claro que la estructura del título no es aleatoria, sino que, por el contrario, es producto de un proceso premeditado de construcción de significados. Por ello, Hernando (2000: 22) afirma que "los titulares ofrecen un notable interés para el investigador". Por ejemplo, ofrecen un importante indicador de la ideología de los propietarios de los medios.

La titulación es uno de los recursos estilísticos más importantes de la redacción periodística de los medios escritos. Clave, sobre todo, es la titulación utilizada en la portada de los periódicos. En ocasiones, por ejemplo, un titular 'llamativo' puede atraer la atención de un transeúnte y provocar la compra del periódico al pregonero. Además, no sería raro que un lector se dé por satisfecho e informado sólo con leer los títulos que aparecen en el diario.

El titular gira alrededor de la función fática del lenguaje (Jakobson), la más descuidada de las funciones a nivel del análisis del discurso. Además, es un programador de la potencial lectura de la noticia y encabeza y condensa el sentido de ésta última. El titular es una macroestructura que resume el contenido de la noticia (Van Dijk 1990). En el marco de las operaciones descriptivas, según el modelo propuesto por Jean-Michel Adam (1999; 2000) responde a la operación de anclaje: es decir, ancla el sentido del texto que encabeza. Por su parte, Barthes (1986), en El mensaje fotográfico, incorpora el titular, en su caso de las fotografías de las noticias, entre los procedimientos connotativos del discurso informativo, apreciación que 
puede extrapolarse al conjunto de los titulares de un periódico. Tan importante es el titular en la redacción periodística que se le han dedicado manuales, como por ejemplo El titular: manual de titulación periodística, de Antonio López Hidalgo (2001).

El titular, por otra parte, ofrece un importante espacio para la creatividad del lenguaje periodístico. En el marco de la evolución del español, es uno de los espacios más innovadores de nuestra sociedad. Este proceso se conoce dentro de la misma práctica periodística como creatividad. Guerrero Salazar (2007) enumera las razones que provocan la creatividad, sobre todo léxica y morfológica, en el discurso periodístico: la necesidad de designar nuevas realidades, la voluntad de estilo, el contagio socio-contextual, la ignorancia y el error, la economía o administración del espacio periodístico y, por último, los recursos de correferencia. Estos últimos tienen carácter anafórico y catafórico.

El presente trabajo, que busca describir aquellos mecanismos lingüísticos utilizados en los titulares de dos diarios nacionales, La Nación y La Extra, propone las siguientes preguntas de investigación: ¿Qué recursos retóricos utiliza la titulación de La Extra y La Nación?; ¿qué estructura sintáctica se emplea en la titulación de La Extra y La Nación?; ¿qué juego de voces se da en la titulación de La Extra y La Nación?; ¿qué procedimientos morfológicos derivativos se dan en la titulación de La Extra y La Nación?; ¿qué inferencias estilísticas e ideológicas podemos extraer a partir de los titulares sobre el proceso productivo periodístico de las empresas de ambos periódicos?

Nuestro objetivo general es el de analizar los recursos lingüísticos utilizados en la titulación periodística de La Extra y La Nación, mientras que nuestros objetivos específicos son, primero, inventariar los recursos retóricos, sintácticos y morfológicos utilizados en la titulación de los periódicos La Extra y La Nación; segundo, identificar el juego de voces empleado (estilo directo, indirecto, indirecto libre); tercero, describir los mecanismos lingüísticos mayoritariamente utilizados por ambos diarios en el proceso de escritura de los titulares y cuarto, analizar la relación entre los recursos lingüísticos más frecuentes en los titulares de cada uno de los diarios y los efectos estilísticos e ideológicos que buscan producir.

\section{Estado de la cuestión e hipótesis}

La titulación periodística ha sido ampliamente investigada, desde diversas perspectivas, enfatizando características como el tiempo verbal utilizado, creatividad lingüística, recursos retóricos, tipo de vocabulario utilizado, entre otros.

Francescutti (2009) estudia el tiempo verbal empleado mayoritariamente en los titulares españoles y concluye que se ha dado un paulatino incremento del uso del presente simple de indicativo desde 1980 hasta el 2005, en detrimento de los titulares no verbales, que aparecen en menores proporciones. Esto permite hablar de una disminución de la nominalización deverbal, fenómeno que será analizado en la presente investigación. Además, identifica diferencias en la titulación de las noticias informativas -que optan por el presente de indicativo- frente a las argumentativas -que se inclinan por sintagmas no verbales-. Francescutti considera que el uso de este tiempo verbal permite al medio transmitir una idea-ilusión- de simultaneidad entre los eventos y su divulgación. Con respecto a este particular, Alcoba (1983) aclara que con el uso del presente de indicativo, en tanto forma relativa, aporta información sobre el acontecimiento, pero no sobre su temporalidad, pues, para averiguar cuándo ocurrió la noticia, habrá que remitirse a la bajada o al cuerpo de ésta. La noticia siempre se redacta el día anterior a su publicación y es, por tanto, un tiempo no decodificable deícticamente. 
Algunas características propias del discurso periodístico han sido estudiadas por Guerrero Salazar (2007). La autora ha analizado la creatividad léxica, y según ella, existen una gran variedad de mecanismos lingüísticos a nivel morfológico, léxico y semántico que se insertan en el lenguaje periodístico y lo revisten de rasgos discursivos propios. La investigadora toma en cuenta muchos recursos, sobre todo los fenómenos de prefijación, sufijación, composición y neologismos de sentido -eufemismos y metáforas-.

Es importante recordar que los procedimientos retóricos no sólo existen en el ámbito literario, sino que se utilizan en la interacción conversacional cotidiana. De ahí se filtran a otros espacios. Así, Cuvardic (2004) afirma que en el espacio político abundan las metáforas; entre ellas, señala las bélicas, las deportivas y las lúdicas. Siendo así, es de esperarse que en el espacio periodístico se presenten este mismo tipo de expresiones, pues cumplen múltiples funciones pragmáticas, con repercusiones en el ámbito social. Por ejemplo, en el nivel cognitivo, Ruiz Gurillo (2000: 201) afirma que la metáfora, las metonimias y las imágenes esquemáticas "aseguran una conceptualización más sencilla y comprensible”. La autora estudia estas expresiones en varios diarios españoles a partir de un mismo tema: la ruptura de la tregua por parte de la banda terrorista ETA.

También se circunscribe al ámbito léxico Nadal Palazón (2008), quien investiga la presencia de la nominalización deverbal. Considera que es un fenómeno muy común en el discurso periodístico y, sobre todo, en el de la titulación. Afirma que su empleo se fundamenta en dos factores, ambos pragmáticos: primero, la economía del lenguaje, fenómeno característico de la titulación, y segundo, la motivación ideológica, en cuyo caso la nominalización deverbal muestra la intención de eludir información relevante, especialmente el agente o las circunstancias de la acción referida. Nadal Palazón analizó 2397 titulares, publicados casi todos en febrero de 2005 en los diarios mexicanos Reforma, El Universal, El Sol de México, La Jornada y La Prensa. Por otra parte, Van Dijk (1997: 172), desde el análisis del discurso, concluye que las minorías étnicas, en los titulares de los periódicos holandeses, quedan principalmente representados como agentes responsables de actos negativos.

Por su parte, Guillermo Sunkel (2002) analiza periódicos amarillistas chilenos y sostiene que los procedimientos humorísticos y la incorporación del lenguaje popular forman parte de los recursos de titulación. Las expresiones cotidianas cumplen la función de llamar la atención del transeúnte, pero también se pueden utilizar toda una serie de recursos lingüísticos que, por su amplia difusión, pueden influir en la forma de hablar de la ciudadanía. Se trata de un proceso de influencia recíproco.

A raíz de los resultados alcanzados por las investigaciones previas, podemos establecer como hipótesis que las implicaciones estilísticas (concisión como principio estilísticos primordial, la necesidad de otorgar la marca de actualidad a la noticia) e ideológicas (ofrecer un punto de vista) de los procedimientos lingüísticos de la titulación empleados en otros países también aparecen en los procedimientos de titulación de los diarios costarricenses.

Se extraerán, de entre estos últimos, los procedimientos más utilizados por cada uno de los diarios en estudio desde el punto de vista de su incidencia estilística e ideológica.

\section{Marco teórico: la socio-semiótica}

El marco teórico utilizado es socio-semiótico. Básicamente, esta teoría propone que el producto discursivo de las instituciones se encuentra determinado por los condicionantes de 
su proceso productivo. Se pueden formular cinco determinantes del proceso productivo en las empresas de comunicación (Hall 1980):

1. Las condiciones tecnológicas (por ejemplo, la carencia de servicios de prensa internacionales determina la ausencia de noticias procedentes de agencias internacionales en las páginas de ciertos periódicos);

2. las relaciones productivas (internas, entre editor y periodista, cuando el primero le asigna al segundo la ejecución de ciertas actividades; y externas, entre periodista y fuente);

3. los valores profesionales (los llamados valores noticia, como son la cercanía geográfica y la cantidad de personas involucradas). Así, por ejemplo, en la prensa costarricense, se prestará más atención a la muerte de diez personas en Costa Rica que a la de cien en China);

4. la ideología de los propietarios (que determina acciones como la censura...);

5. las convenciones genéricas (o, más ampliamente, discursivas); hablamos de los procedimientos narrativos, descriptivos y argumentativos típicos de cada género discursivo.

Los procedimientos lingüísticos de la titulación periodística se encuentran determinados por estos factores, sobre todo por los tres últimos, dado que son factores cognitivos.

\section{Marco metodológico para el estudio de la titulación de la prensa}

La presente investigación es de corte analítico. Se estudiará una práctica del registro profesional periodístico: la titulación. Primero se realizará una investigación exploratoria para reconocer los principales procedimientos lingüísticos en la titulación informativa de La Nación y La Extra, más específicamente en el marco temporal que se inicia el 15 de septiembre y que concluye el 15 de octubre. Posteriormente, se seleccionarán los ejemplos más utilizados y más relevantes de ambos diarios, para proceder a interpretarlos.

Metodológicamente, se buscará extraer inferencias sobre los condicionantes del proceso productivo (explicados en el marco teórico) a partir de los productos discursivos interpretados: los titulares.

La herramienta teórica es el análisis del discurso, desde una perspectiva lingüística, así como la innovación léxica. Los indicadores para rastrear este tipo de innovación en La Nación y La Extra se toman, entre otros, de Salazar Guerrero (2007) y Nadal Palazón (2008).

Según Salazar Guerrero, los procedimientos de creación léxica en el lenguaje periodístico son los siguientes:

1) Neologismos por sufijación. Hablamos de sufijación apreciativa, como son los diminutivos (-illo; -ito) y los aumentativos (-ón/ona; -azo/-aza; -ísimo); de sufijación entre apreciativa y no apreciativa -sufijos semánticamente 'neutrales' que adquieren en algunos contextos sentido disfemístico (-ada, -oso/-osa; -erío/-ería/-ía; -ítis; -oide; ólogo/-óloga; -manía; -cracia) - y de sufijación no apreciativa, tanto nominal (-ismo; -ción; -dad; -miento; -ada; -dor; -aje; -e; -eo), como adjetival (-ista; -al; -ar; -ano/-ana; -ble; -nte; -dor) y verbal (-ear; -izar). 
En este apartado, también se han incluido los neologismos citados por Nadal Palazón producidos mediante la nominalización deverbal, mecanismo de formación de sustantivos a partir de verbos. Los sufijos que este investigador destaca son -ción (grabación), -sión (aprehensión), -miento (acercamiento), -aje (camuflaje), -ura (clausura), -o (maltrato). Casado Velarde (1978: 102), a su vez, menciona dos tipos de nominalización deverbal, o transformación nominal": "la llamada sufijal (el sustantivo aparece incrementado por un sufijo: declarar-declaración) y la postverbal (desprovista de morfema afijal: comenzar-comienzo). Aquí [es decir, en su artículo] las denominaré, respectivamente, progresiva y regresiva).” (en cursiva en el original). Puede aparecer, asimismo, nominalización deadjetival.

2) Neologismos por prefijación. Aparecen en el marco de la semántica de la negación, oposición o contrariedad (anti-; contra-; des-; no); la posición (post-; pre-; inter-; co-; con-; pro-; sobre-; supra-; sub-; infra; -extra; meta-; retro-); el número, la cantidad y el tamaño (bi-; micro-; mini-, uni-; multi-; pluri-; semi-; nano-); la iteración (re-); la calificación (neo-; seudo); la intensificación (super-; mega-; hiper-; macro-; maxi-; extra-; ultra-; archi-); o, por último, mediante la formación de prefijoides o pseudos-prefijos (bio; video-; ciber-; auto-; foto-; tele-; radio-; eco-; euro-; narco-).

3) Por composición. Hablamos, por una parte, de compuestos ortográficos -dos lexemas unidos fonética y gráficamente-, entre verbo y sustantivo, o entre adjetivo y adjetivo, como en rojiblanco-; y, por otra, de compuestos sintagmáticos (donde la unión entre las palabras formantes del compuesto no se ha llevado a cabo, por lo que mantienen la separación gráfica o, alternativamente, aparecen unidas con guión; así sucede entre sustantivo y adjetivo, entre dos sustantivos - como en escuela taller- o entre dos adjetivos).

4) Parasíntesis: proceso de generación de vocablos mediante prefijación y sufijación, en el que ambos se adjuntan simultáneamente a la base sin que exista aisladamente ni prefijo+base, ni base+sufijo (por ejemplo: inservilidad). También puede ocurrir por medio de composición y sufijación (como en cortoplacismo).

5) Siglación: consiste en abreviar un sintagma mediante la unión de las iniciales de cada una de las palabras que lo componen. Este procedimiento forma parte de las presuposiciones típicas desde las que se construye el lenguaje periodístico, ya que la empresa presupone que el lector conocerá el significado de las siglas que incorpora en los titulares (así como en "el TSJA", siglas que provienen del Tribunal Superior de Justicia de Andalucía).

6) Cruces léxicos: unidad léxica conformada por dos lexemas fragmentados que se unen sin separación gráfica ni guión (democradura: cruce entre democracia y dictadura).

7) Acortamientos: reducción del cuerpo fónico de una palabra por la pérdida de sílabas completas (meta por guardameta).

8) Neologismos de sentido: nuevos significados que surgen en significantes ya existentes. Existen los originados por metáfora -proceso muy relevante en el cambio semántico- (como en caerse para referirse a un fallo en el servicio eléctrico) y los originados por eufemismo que buscan no nombrar lo que ya tiene nombre (señor de la droga por traficante). 
9) Frases hechas y expresiones consagradas: clichés, refranes y otros que atraen porque apelan al acervo cultural popular (así como: antes muerto que sencillo).

10) Manipulación del nombre propio. Normalmente, el nombre propio sirve sólo de referencia y no cumple un rol semántico, pero en el lenguaje periodístico se pueden usar nombres propios con significados particulares (maría = marihuana).

11) También analizamos el estilo directo e indirecto, las construcciones sintácticas y el uso de los tiempos verbales.

\section{Resultados de la investigación}

El presente análisis se centrará únicamente en el titular como tal. Si aparecen otros elementos como la volanta (incorporado en este análisis a la derecha del titular y en letra más pequeña) o la bajada (a la izquierda) será con el objetivo de facilitar la decodificación del mensaje y por tanto dilucidar los procedimientos lingüísticos propuestos, lo cual puede ser necesario en algunos casos, entre ellos los neologismos de sentido y las frases hechas. Se omitirán cuando no se consideren relevantes en el análisis del sentido del titular.

En la sufijación apreciativa aumentativa, los ejemplos más relevantes de este tipo de sufijación son los siguientes:

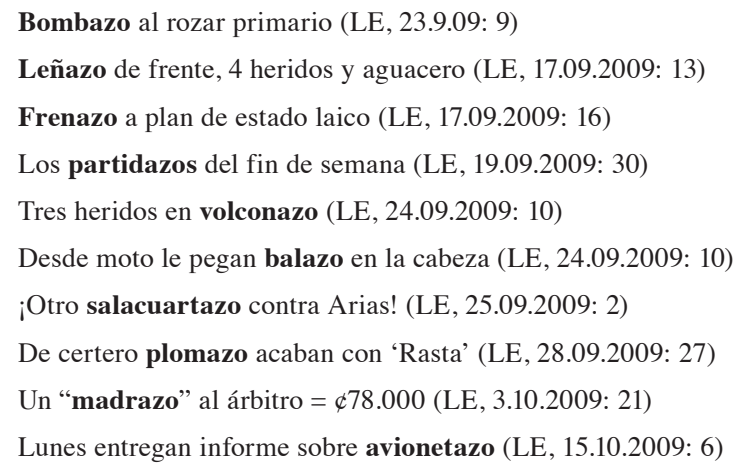

El sufijo -azo es el más productivo en el periódico La Extra y, en este sentido, concuerda el presente estudio con Guerrero (2007: 64), quien afirma que es "el más característico en la neología periodística”. La autora destaca que este sufijo es plurifuncional, lo cual también se demuestra en la prensa de Costa Rica con ejemplos extraídos de La Extra. Su empleo se categoriza como apreciativo en tanto proporciona una valoración subjetiva del acontecimiento. Puede utilizarse para crear un matiz meliorativo en ejemplos como partidazo. Otros usos coinciden con los casos clasificados por Guerrero (2007: 68) como medidas judiciales tomadas con repercusión social llamativa. Tal es el caso de salacuartazo -recurso de defensa de derechos que se presenta a la Sala Cuarta- o avionetazo, término empleado para referirse al hecho de que una diputada utilizó una avioneta perteneciente al Estado para realizar viajes con finalidades políticas y no laborales. En otros casos, se produjeron nombres de acción como en volconazo o frenazo, con los que se busca intensificar el significado original del verbo. Este último caso procede del titular "Frenazo a plan de estado laico", en el cual la nominalización introduce una metaforización del proceso de toma de decisiones en la Asamblea Legislativa. En otro titular, el sufijo - azo aparece también formando parte de una palabra a la cual modifica 
semánticamente, pues madrazo es una expresión consagrada en el habla popular como insulto. Los otros usos del sufijo caben dentro de la clasificación de 'golpe dado por': balazo, leñazo, bombazo y plomazo. Por su parte, este sufijo no goza de prestigio en el diario La Nación.

Ejemplos de sufijación apreciativa diminutiva son los siguientes:

Ante la 'Negrita' (LE, 6.10.2009: 1)

Fiestica en las pirámides (LE, 7.10.2009: 21)

Viejitos podrán viajar gratis en tren (LE, 9.10.2009: 2)

Dentro de esta subcategoría sobresale el sufijo apreciativo diminutivo -it con valoración positiva en la palabra viejito, la cual se usa a nivel nacional para referirse a las personas de la tercera edad de manera afectiva. Por su parte, llamar a la Virgen de los Ángeles "La Negrita" se hace con un sentido de estimación familiar y ya se ha convertido en la forma más común de referirse a ella. Caso particular es el de "fiestica", que aparece en un titular deportivo a propósito de un partido de la selección Sub20 en Egipto. La creatividad de este titular puede explicarse desde dos perspectivas: por un lado, puede decodificarse como la utilización del sufijo -ic de diminutivo, que es el más usado en Costa Rica en la oralidad como producto de una disimilación, cuando la raíz de la palabra ya posee una /t/ como fiesta. Por otro lado, puede entenderse como una composición sustantivo + adjetivo: fiesta + tica. En cualquiera de los dos casos, implica alegría experimentada tanto por los jugadores como por la afición (entendida como toda la ciudadanía). El hecho de que los fenómenos tengan más que una posible explicación semántica enriquece el proceso lingüístico enunciador y la decodificación del mensaje.

\section{deverbal:}

Hemos encontrado, entre otros, los siguientes ejemplos de sufijación no apreciativa

Caluroso recibimiento a antorcha de independencia (LE, 15.09.2009: 2)

Caída frenó a Gregory Brenes (LE, 24.09.2009: 24)

Piden destitución de director (LE, 25.09.2009: 17)

Represión a zelayistas y asedio a embajada de Brasil en Honduras (LE, 23.09.2009: 17)

Vuelco de carro deja a dos graves (LE, 1.10.2009: 14)

Lluvias provocan cierre de carretera (LE, 5.10.2009: 28)

El sufijo -sión/-ción es el más productivo. Es importante recordar que todos estos mecanismos lingüísticos cumplen la misma función: economía de espacio. La nominalización deverbal aparece en diferentes posiciones del titular y no necesariamente como el primer elemento. Nótese, por ejemplo, que si no se utilizara la nominalización deverbal ni ningún otro recurso para reducir enunciaciones, un título como "Vuelco de carro deja a dos graves" tendría que estar constituido por dos oraciones: "Un carro se volcó y dejó como consecuencia dos personas gravemente heridas". El efecto consecuente sería información demasiado extensa como para captar la atención instantánea del transeúnte.

Según las estructuras halladas, este apartado se apega más al enfoque de Nadal Palazón que al de Guerrero, pues el primer autor destaca estas construcciones en tanto eliden el agente y permiten reducir una oración a un nombre (Nadal Palazón 2008: 179), mientras la segunda autora aborda el tema desde la perspectiva de creación de nuevos significantes, lo cual no ocurre en los ejemplos extraídos. El recurso se utiliza efectivamente en La Extra, mas no de forma exhaustiva. 
En La Nación, el uso de la nominalización deverbal también se reportó, aunque en menor escala que en La Extra:

\author{
Incremento en precios de combustibles rige mañana (LN, 17.09.2009: 1A) \\ Venta libre a píldora del día después (LN, 27.09.2009: 18A) \\ La desaparición del almuerzo gratis (LN,10.10. 2009: 24A) \\ Cierre de compañía eléctrica en México desata furia sindical (LN, 13.10.2009: 23A)
}

En el primer caso, se utiliza la nominalización en lugar de "Los precios subirán a partir de mañana"; en el segundo, en lugar de "Se vende a partir de hoy la píldora del día después"; en el tercero, que además es un enunciado exclusivamente nominal, en lugar de "desaparece el almuerzo gratis (en Cuba)"; en el cuarto, en lugar de "cerrarán compañía eléctrica en México".

Estas nominalizaciones deverbales o de acción, al eliminar algunos argumentos (término de la gramática funcional) en casos en los que se conoce el agente que instiga el acontecimiento, cumplen una función ideológica clara: "el proceso nominalizador se presenta la mayoría de las veces como si fuera espontáneo, a pesar de tratarse de derivados de formas léxicas cuya estructura semántica exige o presupone la existencia de entidades animadas que instigan, controlan y dirigen la acción representada"; este procedimiento contribuye a configurar textos estáticos, ya que "al convertir un proceso verbal en sustantivo, es decir, al mostrar una acción como si fuera un objeto, la relación entre procesos y participantes se muestra inmóvil." (Nadal Palazón 2008: 183). El lector que lea exclusivamente los titulares se preguntará: ¿quién incrementará los precios?; ¿quién permitirá la venta de la píldora del día después?; ¿quién y por qué cerrará los comedores gratuitos en Cuba?; ¿quién y porqué cerrará la compañía eléctrica? Ahora bien, su empleo también está motivado por la concisión buscada en el titular.

La sufijación no apreciativa nominal es bastante productiva en La Extra en la formación de la nomenclatura de los empleos:

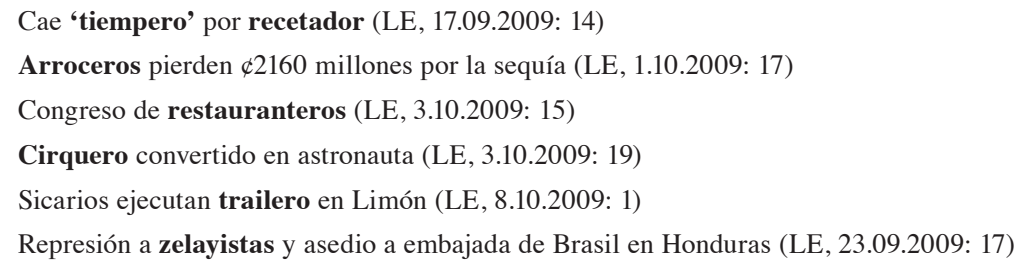

$\mathrm{Su}$ uso puede ser convencional, como en "trailero", o bien creativo. Por ejemplo, el discurso periodístico crea "tiempero" - persona que vende el tipo de lotería denominada "tiempos"- o "restaurantero" - dueño de un restaurante-. Se reportó el sufijo -ista como individuo perteneciente a una tendencia política -zelayista- o bien como "persona que trabaja para o en" -cruzrojista-. El sufijo - ero se vincula más con los costarriqueñismos, mientras que el uso de -ista forma parte integral de todas las variedades dialectales del español. Por su parte, entre los escasos neologismos mediante sufijación no apreciativa en La Nación se presentó el siguiente: "Precarismo" (LN, 27.09.2009: 1A).

También se presentaron casos de sufijación no apreciativa adjetival en La Extra, sobre todo para la formación de gentilicios:

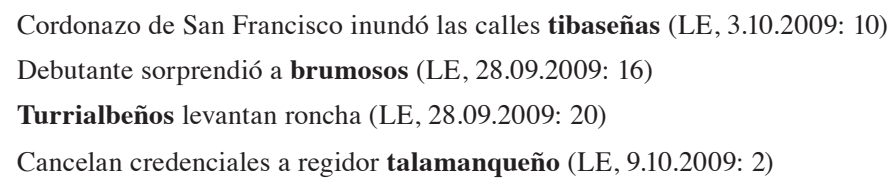


Dentro de este subgrupo, también se registró un titular cuyos únicos componentes eran dos adjetivos, conformados a partir de los participios de los verbos cansar y carbonear: “Cansados y Carboneados" (LE, 30.09.2009: 21). A partir de este último vocablo, surge un significado dialectal particular. Según Quesada Pacheco, en su Nuevo Diccionario de Costarriqueñismos (2007: 100), carbonear significa "incitar a uno contra otro, encizañar, introducir recelo o ánimo"; en consecuencia, "carboneado" se decodifica como "persona a quien se le ha metido cizaña contra algo o alguien".

La nominación deadjetival es rara en la titulación de La Nación. Se utilizó sobre todo para reducir la frase nominal una persona detenida a detenido, procedimiento común en la sección de Sucesos: "Detenido por secuestro fue condenado en Panamá” (LN, 28.09.2009: 16A). Aquí la función ideológica es clara: la acción define al sujeto.

En el caso de la prefijación, esta categoría no resultó productiva en el caso de $L a$ Extra ni de La Nación, aún cuando Guerrero ha manifestado que son de gran relevancia en la prensa española. Aparecen en La Extra los prefijos vice- y ex-, los cuales no se utilizaron con énfasis imaginativo, sino más bien a manera de lenguaje estándar: "Diputado de "mano dura" aspira a vicepresidente" (LE, 5.10.2009: 6); "Cantó a ex cuñado con el OIJ" (LE, 22.09.2009: 10). Otro tanto sucede con La Nación: “Anticonceptivos serían aliados contra cambio climático" (LN, 19.09.2009: 16A).

La composición no es un fenómeno muy recurrente en La Extra, pero en los casos que se usó hubo un manejo imaginativo de las estructuras lingüísticas constitutivas del mensaje:

\footnotetext{
Sustantivo +sustantivo + sufijo aumentativo: ;Otro salacuartazo contra Arias! (LE, 25.09.2009: 2)

Sustantivo +sustantivo: Juez detuvo policaco que "limpiaba" su cas" (LE, 3.10.2009: 13)

Sustantivo + adjetivo: Gol del tractor Félix Montoya, Herediano 2 - Brujas 1 "Felixes" de la vida (LE, 5.10.2009: 18)
}

Sustantivo + adjetivo: Fiestica en las pirámides (LE, 7.10.2009: 21)

Ejemplos de compuestos sintagmáticos son los siguientes: "Así se informó en el mundo la sentencia Caja-Fischel” (LE, 6.10.2009: 11); "Cadena de escándalos en caso CCSSFischel" (LE, 6.10.2009: 17).

En La Nación, también apareció este último compuesto sintagmático: "Alianza PUSC-Fischel" (LN, 6.10.2009: 1). Este tipo de compuesto se utiliza mucho en situaciones conflictivas, como modo de condensar el sentido y establecer una etiqueta que pueda ser manejada por todos (instituciones y ciudadanos).

De los titulares anteriores, sobresale la unión sintagmática CCSS-Fischel o CajaFischel para referirse al juicio en torno al famoso caso del ex-presidente Calderón Fournier. Este ejemplo se considera relevante en tanto permite la economía de espacio y la unión tanto de dos sustantivos como de siglas y sustantivos. En este segundo caso, las siglas llegan a ser manipuladas como verdaderos sustantivos.

Otro recurso usado es la unión sustantivo +sustantivo + sufijo aumentativo para crear el vocablo salacuartazo, instaurado en el habla de los costarricenses para referirse a una demanda en defensa de derechos individuales o colectivos que toma lugar en la Sala Cuarta.

Las composiciones con función propiamente creativa que se registraron fueron policaco -policía + caco (ladrón)-, que produce un encuentro de expectativas, pues se espera que los policías cuiden a los ciudadanos y no que ellos mismos sean los ladrones. Se trata de una composición paradójica. 
En Felixes, -Félix + felices-, se utiliza el nombre propio del jugador de fútbol para hacer énfasis en los sentimientos producidos por su efectivo desempeño en el partido, mientras que Fiestica, -fiesta+tica-, puede ser interpretada como una gran celebración de los costarricenses por los resultados de la selección Sub20 obtenidos en Egipto.

Son mucho más escasos los compuestos en La Nación. Entre las excepciones, podemos destacar: "Se busca un 'apagaincendios"” (LN, 15.09.2009: 35A); "Nuevo papel se "autoborra"” (LN, 16.09. 2009: 14A).

Por su parte, el recurso de siglación está justificado en tanto el enunciador reconoce en el destinatario, es decir, en los lectores, el significado de este procedimiento. Ha de entenderse la presuposición pragmática como el supuesto que el hablante hace sobre lo que probablemente aceptará el oyente sin ponerlo en duda (Brown y Yule 1983: 51).

Las siglas fueron ampliamente utilizadas tanto en La Extra como en La Nación. La prensa presupone un lector con amplio conocimiento de las denominaciones institucionales de las organizaciones nacionales, Caja Costarricense de Seguro Social, Instituto Nacional de Vivienda y Urbanismo, Organismo de Investigación Judicial, entre otras; o bien del nombre de los partidos políticos interesados en participar en las próximas elecciones como el Partido Acción Ciudadana, Partido Liberación Nacional y Partido Unidad Social Cristiana:

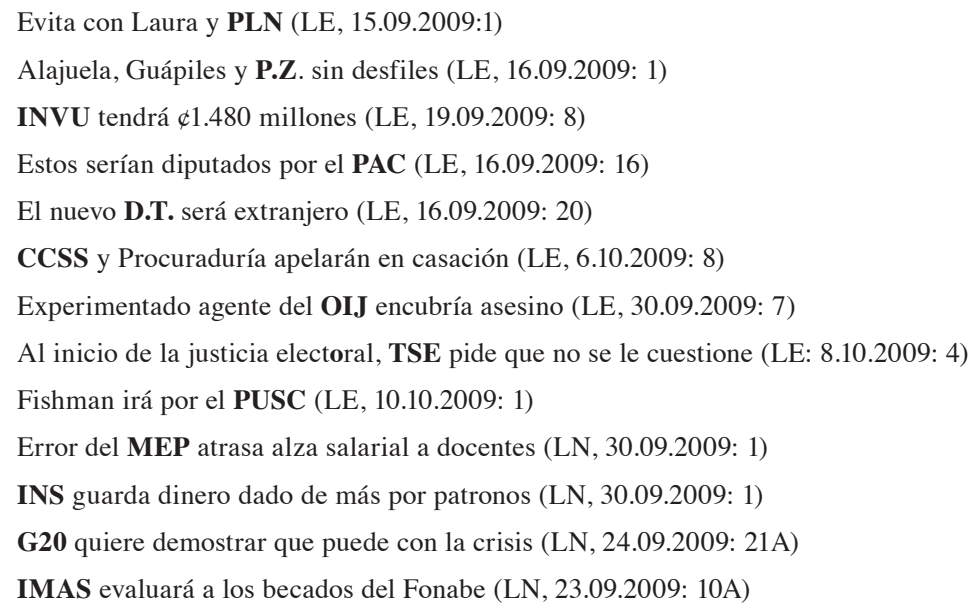

Es interesante destacar el uso de las siglas P.Z. registrado en La Extra, pues a partir de ellas se ha popularizado el gentilicio "pecetero" para los habitantes de Pérez Zeledón. Este caso particular cumple una doble funcionalidad: dirigir el discurso a las clases populares y que estas vean reflejadas su forma de hablar, así como lograr mayor economía de espacio en el titular. Por su parte, la decodificación de siglas como D.T. -Director Técnico- ya no es tan automática y muchos lectores se verán en la necesidad de leer el principio de la noticia para entender su contenido. En este último caso, es evidente que la única finalidad para usar estas siglas es reducir la extensión del titular al máximo posible. Es interesante comprobar que cuando la siglación involucra el uso la extracción de sílabas, y no de las letras iniciales, se usa la minúscula, como en el titular de La Nación: Fonabe.

Las presuposiciones motivan la concisión informativa de muchos titulares en el ámbito de la identificación de personalidades públicas. Por ejemplo, en "Zapatero ofrece a Obama respaldo en Afganistán" (LN, 14.10.2009: 24A), se presupone que los lectores saben que Zapatero es el presidente del gobierno español, que Obama es el presidente de los Estados 
Unidos, que en Afganistán se vive una situación de guerra y que en los últimos meses el gobierno estadounidense ha buscado mayor apoyo de sus aliados en la 'misión de paz' que la OTAN tiene en este país asiático. Ocurre lo mismo en La Extra con el uso de nombres propios, apellidos o nombres de compañías sin especificación del referente:

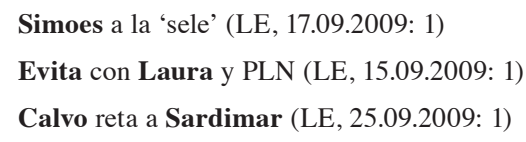

No se considera necesario brindar información adicional explicando, por ejemplo, quién es Laura o qué clase de productos venden las empresas Calvo o Sardimar. En todos los titulares periodísticos, podemos extraer este tipo de enunciados presupuestos.

Un caso que no es de siglación, sino de inicial prácticamente convertida en símbolo de una entidad, es S por o en lugar de Saprissa: "A pesar del punto, 'S' la tiene difícil" (LN, 23.09.2009: 36A).

Los acortamientos son recurrentes en el devenir discursivo de La Extra:

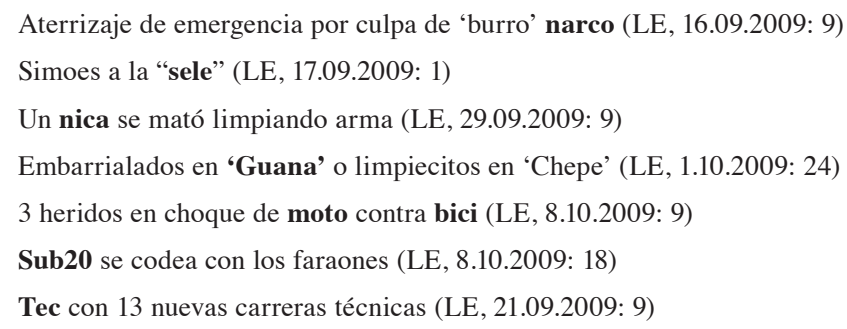

Son relevantes en tanto constituyen otro vínculo con el habla cotidiana de los costarricenses, pues aquellos que se usaron no provienen de decisiones arbitrarias del periodista, sino más bien de las formas que diariamente se utilizan en las conversaciones. Por lo demás, sirven a la economía del titular.

Por su parte, prácticamente el único Acortamiento presente en La Nación se da con la palabra Sele: "Simoes ve a la Sele con buenas posibilidades" (LN, 17.09.2009: 30A).

Los tropos, por otra parte, son muy productivos en la titulación. La retórica está presente tanto en el lenguaje coloquial (Lakoff y Johnson 1986) como en el especializado. No es distinto el caso del discurso periodístico, donde son comunes las figuras de carácter semántico (o tropos), más que las figuras de carácter sintáctico (posición, amplificación, reducción, repetición...). Son numerosas las metáforas, así como sus modalidades más especializadas (metonimia, sinécdoque...). En su función creativa, las metáforas, incluso, cuentan con la función de atraer la atención del lector, al renovar la comprensión del mundo. El lector presta más atención al titular al desfamiliarizar o desautomatizar la percepción.

Tanto en La Extra como en La Nación, se utiliza bastante la metáfora bélica en la sección deportiva. Se refuerza el carácter competitivo del fútbol, al asociarlo con la guerra misma. En estos enunciados metafóricos, el equipo y los jugadores llegan a 'arriesgar su vida' en la cancha, tal y como ocurriría en una batalla real: “¡Guerra en el Morera!” (LE, 26.09.2009: 23); “"Monstruo' se juega la vida” (LE, 22.09.2009: 22). Las mascotas de los equipos más famosos se consagran como verdaderos símbolos y, por tanto, llegan a ser sus representantes por antonomasia: "El monstruo lucha por su vida" (LE, 30.09.2009: 1). En consecuencia, 
un insulto o falta de respeto al símbolo implica una burla a todo el club deportivo: "Fuera del Morera es un lindo gatito" (LE, 21.09.2009: 12). En este caso, se establece una comparación del León -mascota de la Liga Deportiva Alajuelense- con un gato; es decir, se reduce su peligrosidad. Este efecto se intensifica por medio de la sufijación diminutiva. Esto implica que, a partir del rasgo +felino, se degenera una imagen fuerte y salvaje en una débil, doméstica y pequeña, casi indefensa. Ahora bien, si se analiza este titular desde la intertextualidad, aparece el referente de una fábula muy famosa en la que un pájaro llamado Piolín siempre logra escapar de las garras del gato Silvestre, a quien se refiere con las palabras: "Me pareció ver un lindo gatito". Este nexo refuerza la primera interpretación, pues si el lindo gatito del titular se refiere a Silvestre, lo haría bajo el entendido de que es torpe y nunca logrará cumplir sus objetivos.

La Nación también usó metáforas en los titulares. Algunos casos son:

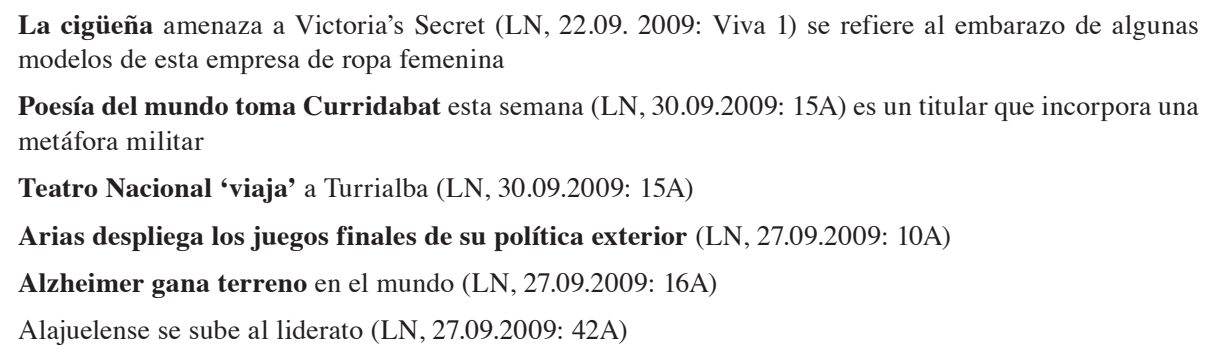

A partir de los ejemplos ofrecidos, se observa que el uso de las metáforas no sólo se circunscribe a la sección deportiva, sino a otras secciones, sobre todo la de espectáculos. Este recurso, en cambio, es mínimo en secciones como política o sucesos.

Gran parte de las metáforas que utiliza el ser humano son orientacionales (Lakoff y Johnson 1986). Arriba es positivo y abajo negativo o adelante es progreso o cambio, como sucede en el siguiente titular: "La radio se mueve" (LN, 28.09. 2009: 1Viva) por "cambios empresariales en las emisoras de radio". Por otra parte, "Sabina desnudará su alma en Vinagre y rosas" (LN, 28.09. 2009: 8Viva) significa que dicho cantante expresará sus sentimientos en su último disco. "Costa Rica fue presa fácil de un Brasil letal" (28.09.2009: 49A) manifiesta el hecho de que la selección de Costa Rica fue derrotada en el partido de fútbol por un equipo brasileño que jugó mejor y lo hace por medio de una analogía: ganador es a depredador como perdedor es a presa.

Una metáfora peculiar es el titular "Gobierno pasa el sombrero en Nueva York" (LN, 23.09.2009: 6A). Pasar el sombrero se puede traducir por otro verbo, también utilizado metafóricamente, mendigar, en el sentido de buscar ayuda económica. Dicho enunciado resulta controversial, pues podría decodificarse como una crítica en contra del gobierno, en el entendido de que el país no produce sus propios recursos económicos sino que debe pedir limosna a otras naciones.

Los titulares llegan a ser tan creativos que se convierten en alegorías (es decir, se recrean situaciones alegóricas), ya sea porque contienen dos o más metáforas, o porque permiten al lector imaginar toda una nueva situación a partir de los elementos linguíísticos utilizados. En el período analizado, esto ocurrió sobre todo durante el campeonato de la selección sub20 de fútbol. A partir de los titulares, se pueden recrear alegóricamente todas las vivencias de los deportistas, asociándolas con los elementos más representativos de Egipto: 


\author{
Durmiendo con los faraones (LE, 23.09.2009: 20) \\ Costa Rica 0 Brasil 5 Pesadilla en las pirámides (LE, 28.09.2009: 23) \\ Costa Rica-Australia hoy a las 8 a.m. Cuidado nos sacan las 'canguro' (LE, 30.09.2009: 20) \\ Costa Rica 3-Australia 0 ¡No se bajan del camello! (LE, 1.10.2009: 20) \\ Los dejamos momificados (LE 7.10. 2009: 20) \\ Fiestica en las pirámides (LE 7.10. 2009: 20) \\ Sub20 se codea con los faraones (LE, 8.10.2009: 18)
}

Hay una gran cantidad de situaciones en las cuales resulta fácil imaginarse a los jugadores en una fiesta con los faraones como amigos, montando camellos o teniendo diferentes vivencias dentro de las pirámides. También, destaca el titular "Cuidado nos sacan las "canguro", pues posee dos metáforas fusionadas en un enunciado, al referirse a los canguros como símbolo de Australia y por tanto de sus jugadores - a propósito del partido contra dicho país- y al mismo tiempo remitir a la marca de bolsas de basura muy utilizadas a nivel nacional. O sea, dentro de este titular yace la siguiente idea: "Cuidado los canguros nos sacan en las bolsas canguro", la cual se interpreta como "cuidado los australianos nos sacan del torneo". Además, destaca el uso del pronombre de objeto nos, pues su aparición implica que el periodista se está incluyendo a sí mismo, al periódico y a la ciudadanía costarricense dentro del grupo que se eliminaría.

Por su parte, en La Nación, casos de alegorías son los siguientes:

'Tierra Dominicana' es la gran 'oficina' del hampa de San José (LN, 11.10.2009: 4A)

La Uruca es el 'mall' más grande de autos nuevos (LN, 14.10.2009: 19A)

Brasil despertó a la Juvenil de su sueño (LN, 14.10.2009: 33A)

El boleto se escurrió en los últimos segundos (LN, 15.10.2009: 36A) -con ocasión del empate con EE.UU-

'Oficina' se refiere a la utilización de un barrio de San José como lugar donde los delincuentes se organizan para cometer futuros delitos. Además, hampa es un disfemismo de delincuentes. En el caso de La Uruca, las agencias serían los diferentes comercios del 'mall', por lo demás, una de las escasas palabras en inglés, junto con 'show', que aparecieron en $L a$ Nación durante el mes sometido a estudio. Brasil, por su parte, es una personificación que despierta de un sueño idílico a la Selección Juvenil de Costa Rica. En el caso del boleto, se puede ampliar la descripción metafórica: el boleto se escurrió por la alcantarilla. Es decir, se perdió el pase a la fase final del Mundial.

Aparecen también en La Extra prosopopeyas o personificaciones como "Virilla se tragó niño" (LE, 15.09.2009: 1), "Mar se tragó a dos gringos" (LE, 5.10.2009: 28); "País se vistió de blanco, azul y rojo" (LE, 16.09.2009: 6); sinécdoques como "Fuego de libertad" (LE,15.09.2009: 1), en donde el fuego se toma como la antorcha de la independencia; e incluso se utilizan hipérboles como "Les falta flotador" (LE, 28.09.2009: 17), para referirse a la magnitud del agua caída durante un aguacero que obligó a suspender el partido de Santos contra Pérez Zeledón.

Algunas sinécdoques de La Nación son: "Jerusalén descarta investigación independiente" (LN, 17. 09.2009: 21 A); “Teherán prueba misil capaz de llegar a territorio israelî" (LN, 29.09.2009: 22A); "69 jugadores se vistieron de rojo en la era Kenton" (LN, 16.09.2009: 28A). En los titulares de la Sección Internacional, es muy común el uso de este tipo de sinécdoques: se menciona la capital del país, en lugar del Gobierno nacional. Así sucede 
con Jerusalén, en lugar de Israel, o Teherán, en lugar de Irán. Vestir de rojo, por su parte, es sinécdoque de vestir el uniforme de la selección nacional de fútbol.

Las metonimias son escasas. Es posible que la economía del titular motive su utilización, como sucede en el siguiente caso, metonimia de causa por (en lugar del) efecto, "Instalación eléctrica mal hecha deja en la calle a 30 personas" (LN, 25.09.2009: 13A), en lugar de "Incendio provocado por instalación eléctrica...".

Un raro caso de reticencia o aposiopesis, que por lo demás es muy corriente en la publicidad de productos del área de la sexualidad, así como en la sección de obituarios ('descanse en paz') se presenta en el titular "Viejo templo parroquial de Puriscal cerró sus puertas... para siempre" (LN, 10.10.2009: 10A). Se prefiere este titular en lugar de "Templo de Puriscal será demolido". La reticencia es muy utilizada al hablar de religión, sexo o muerte, como sucede con "Se apagó la voz de Luis Aguilé" en lugar de Ha muerto Luis Aguilé (LN, 11.10.2009: 1Viva). Las esquelas de los obituarios, géneros que nos permite asociar lenguaje y emociones, recurren a la reticencia.

El recurso de las frases hechas y las expresiones consagradas se manifiesta especialmente productivo en La Extra:

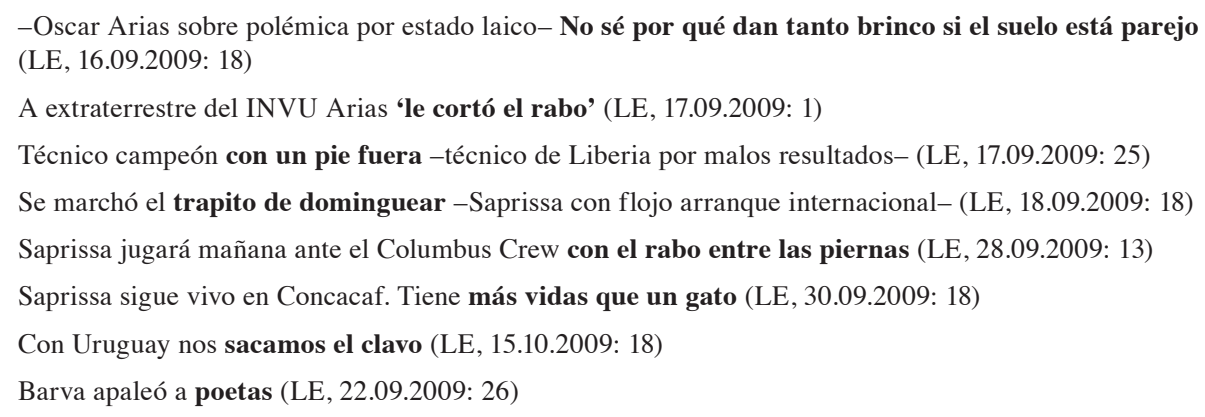

Todas las expresiones recopiladas provienen de una metaforización que ha perdido su carácter "original" o "singular" hasta llegar a consagrarse popularmente, al estilo de los refranes. Se utilizan para decir en pocas palabras, y por medio de comparaciones, lo que de otra manera necesitaría muchas más estructuras lingüísticas. El caso del titular "Tiene más vidas que un gato", se basa en una expresión popular que hiperboliza la habilidad y flexibilidad de los felinos para sortear situaciones difíciles. Se establece una comparación entre los gatos y el Deportivo Saprissa, pues, aún con dificultades, ambos salen adelante. Por su parte, “Con el rabo entre las piernas", posee una expresión que ya se utiliza en El Quijote (Cervantes 2001: 149). Esta expresión se difundió en Costa Rica a partir de una famosa serie mexicana, El Chavo del Ocho, parte de la programación nacional por décadas. Por supuesto, su uso en La Extra remite a la comparación de un perro regañado con un equipo de fútbol -El Deportivo Saprissa- cuyo desempeño en el campeonato de la CONCACAF no había sido sobresaliente,y esto le obligó a deponer su orgullo. Puede verse, entonces, que el límite entre las frases hechas y las metáforas es bastante difuso y radica básicamente en la frecuencia de uso de la expresión. En el último de los ejemplos adjuntos, "Barva apaleó a poetas", se presupone el conocimiento de la expresión Ciudad Poeta como equivalente a San Ramón. De ella deviene el gentilicio poeta $=$ ramonense.

En La Nación, las expresiones hechas o consagradas son bastante escasas. Sin embargo, cabe mencionar: "Política monetaria en la mira" (LN, 28.09: 33A); "Un Saprissa 
maltrecho busca 'sueño americano"” (LN, 29.09.2009: 35A) o "Ambición llevó a vecinos a caer en 'timo del misionero"'(LN, 10.10.2009: 12A).

En ambos periódicos, se presentaron muy pocos casos de neologismos provenientes de otros idiomas. Una excepción de La Nación es la siguiente: "Show pondrá a prueba la masculinidad" (LN, 15.09.2009: 20Viva). Por otra parte, en los titulares de La Extra, el inglés estuvo completamente ausente. El único neologismo de lengua extranjera proviene del portugués, a propósito del origen del nuevo director técnico de la Selección Nacional de Fútbol: "Vamos a "jogarles" bonito" (LE, 26.09.2009: 25).

El estilo directo e indirecto en la construcción de titulares es una de las áreas más complejas de investigación y, al mismo tiempo, más productivas. En La Extra, una gran mayoría de los titulares se presentan como aseveraciones. En cuanto a La Nación, también la conformación de los titulares, en su mayor parte, responde a actos de habla asertivos en presente: el propósito es certificar la existencia de un referente social, sin declarar la fuente de donde proviene el enunciado que refiere este referente. La Nación sustituye el titular de discurso reproducido de la fuente por el titular simplemente asertivo, como en: "Mañana rige aumento en precio de combustibles" (LN 17. 09.2009: 6A).

En estos casos, la idea que impera es que nadie toma las decisiones ni es responsable de acontecimientos que, en última instancia, han sido provocados por elecciones humanas conscientes. Otro caso es el siguiente: "Fugas provocan pérdida del 30\% de agua en la GAM" (LN, 26.09.2009: 4A). Un titular que incorporase eventualmente la fuente informativa estaría redactado así: "Fuentes del AyA reconocen que fugas provocan la pérdida del $30 \%$ de agua potable en el GAM". Puede observarse la tendencia a recuperar o mostrar el origen del discurso reproducido por el diario en el cuerpo de la noticia, no en el titular. En el caso que nos ocupa, el segundo párrafo del cuerpo de la noticia declara la fuente de la información: "Así lo reconocieron autoridades del Instituto Costarricense de Acueductos y Alcantarillados (AyA)" (LN, 26.09.2009: 4A).

No debe extrañar que investigadores como Escribano (2007), al analizar el discurso reproducido en el discurso informativo, decidan hacerlo sobre los sucesos electorales, ya que el acontecer político está basado exclusivamente en acontecimientos discursivos, en actos de habla emitidos por actores políticos que son, asimismo, fuentes cuyo discurso quedará reproducido en el discurso informativo, a diferencia de lo que ocurre con sucesos como los delictivos o los desastres naturales, donde predominan acciones que podemos llamar ejecutivas (joven disparó o terremoto mató). En principio, lo importante de un enunciado político emitido públicamente -muchas veces circunscrito a las simples valoraciones- radica únicamente en quién lo emitió.

Cuando se incorpora la voz de los participantes, aparecen enunciados completos extraídos de afirmaciones hechas por alguno de los involucrados en el acontecimiento, sean protagonistas, testigos o expertos en la materia.

En el ámbito de los titulares con fuente reproducida, surgen varias posibilidades. Es interesante notar que, en caso de utilizarse el discurso directo, no se elide información con respecto al enunciador. Por el contrario, queda identificado desde el rol social, académico o afectivo que lo involucra con la noticia. En estos casos, los titulares presentan discursos directos bimembres con las acotaciones entrecomilladas para indicar que no pertenecen a la voz del periodista. No obstante, hay que recordar que la cita directa es producto de un proceso de selección: el periodista escoge la parte que le del discurso del actor social. Por este motivo, 
incluso en los titulares con cita directa reproducida de las fuentes, el énfasis que se le quiere dar a esta última está filtrada por objetivos específicos del medio de comunicación. Algunos ejemplos tomados de La Extra son los siguientes:

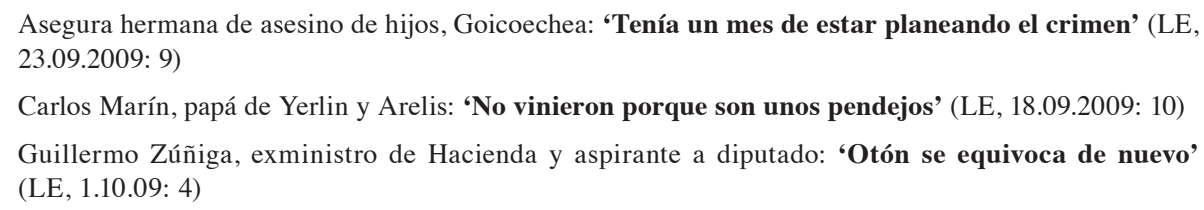

En La Nación, igual de escasa es la cita directa bimembre, donde aparece yuxtapuesto cada responsable de la cita y su respectiva declaración: "Ministra de hacienda, Jenny Phillips: 'Podría haber problemas para pagar aguinaldos"” (LN, 2.10.2009: 9A), o "Dall'Anese: 'La justicia no ve condiciones económicas"” (LN, 6.10.2009: 6A).

Sólo en contadas ocasiones aparece una cita directa sin sujeto. Prácticamente sólo sucede en las entrevistas, y especialmente a personalidades del mundo deportivo: "Con 12 puntos, Costa Rica es una selección fuerte" (LN, 17. 09.2009: 31A). En estos casos, en la volanta, en la bajada o en el cuerpo de la noticia aparecerá la fuente de la declaración. En el ejemplo anterior, la identificación de la fuente de esta declaración aparece en el co-texto circundante (la noticia adyacente), que hablan del nuevo seleccionador de fútbol de Costa Rica. En este punto, se concuerda con la propuesta de Escribano (2007: 67) cuando afirma que este tipo de cita, la directa sin sujeto, es un excelente ejemplo de función fática: "resulta un método bastante eficaz para conseguir mantener la atención del lector, ya que éste, si quiere saber quién es el sujeto responsable tiene que continuar la lectura del texto". Es decir, la intencionalidad es crear el efecto de suspenso, procedimiento que aparece en otros casos (véase más adelante).

Las citas directas con palabra entrecomillada también son escasas en La Nación. En este rubro, consideramos que habría que diferenciar cuando las palabras entrecomilladas provienen de la fuente (en cuyo caso hablamos de discurso reproducido), de aquellos casos en las que proceden del discurso de los periodistas, en titulares que no usan el discurso reproducido. Casos del primer tipo -que no son casos de discurso irónico, por más que las comillas sean marcadores de ironía en el discurso periodístico- son los siguientes: "Presidente avala corregir 'error' sobre Estado" (LN, 16.09.2009: 4A); "Sobrado exige al Gobierno respetar veda 'sin trampas" (LN, 8.10.2009: 5A); "Arias reitera su promesa de una 'total neutralidad"' (LN, 8.10.2009: 5A); "Policía montó 'show', alega exdiputado sancarleño" (LN, 6.10.2009: 13A); "Insulza 'satisfecho' por avances en Tegucigalpa” (LN, 15.10.2009: 26A).

La cita directa con verba dicendi, del tipo X anuncia + "cita directa entrecomillada de la declaración", se encuentra ausente de La Nación, así como en La Extra. Aparecen en La Nación, en cambio, casos de cita indirecta, donde "interesa más reconstruir el sentido general de las declaraciones que su forma original" (Escribano 2007: 70). En todo caso, son escasos, al igual que las modalidades mencionadas hasta ahora. Así sucede incluso en la sección política, donde la noticia radica en el hecho de que un rol institucional emite una opinión o una declaración. A continuación se presentan algunas excepciones:

Pescador asegura que casa decomisada vale c50 millones (LN, 2.10.2009: 11A)

Ejecutivo minimiza caso de helicóptero del ICE (LN, 1.10.2009: 6A)

Arias advierte sobre grupos extremistas en el país (LN, 15.09.2009: 8A) 
Evidentemente, la cita indirecta implica mayor grado de manipulación ideológica que la cita directa. En esta última, la decisión ideológica radica únicamente en elegir un enunciado específico del conjunto de la declaración de la fuente, mientras que en la cita indirecta el periodista que redacta el titular se arroga, además, la autoridad de cambiar algunas palabras del enunciado elegido. Siguiendo a Escribano "[...] puede producirse un sesgo subjetivo, ya que no se trata sólo de informar de lo que se ha dicho, sino también de interpretar la intención que se oculta tras las declaraciones o la manera de realizarse estas" (2007: 70-71).

Enunciados asertivos del periodista con palabras entrecomilladas que expresan la subjetividad del periodista aparecen en diversas oportunidades. En algunos pocos casos, aparecen una o dos palabras entre comillas, las cuales corresponden a la voz del periodista, quien se incluye aportando su punto de vista ante los hechos ocurridos o bien enfatizando la función irónica de la palabra entrecomillada:

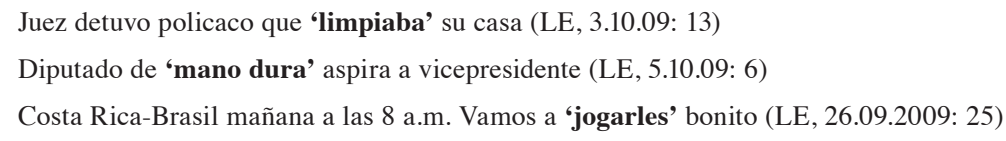

En este último, ejemplo interesa destacar que el periodista hace uso de una palabra extranjera -la única que se reportó durante el mes de recopilación de datos- procedente del portugués “jogar”. Este vocablo fue utilizado para referirse a una situación que involucraba al nuevo entrenador de la Selección Nacional de Fútbol René Simoes, de origen brasileño. Incluir en el titular léxico portugués permite hacer juegos con el lenguaje, de tal manera que el lector pueda imaginarse la situación comunicativa a cabalidad y hasta incluir en el imaginario el acento y palabras que pudieron haberse dado.

Otro caso, en La Nación, aparece en el caso CCSS-Fischel: "Jóvenes hicieron 'fiesta' a la entrada del Tribunal" (LN, 6.10.2009: 6), en referencia a la manifestación de apoyo hacia Rafael Ángel Calderón. En estos últimos casos, la empresa periodística otorga una valoración a las palabras entrecomilladas. Escribano considera que "con frecuencia, los términos que se subrayan entre comillas están cargados de valoraciones" (2007: 70). Fiesta, palabra entrecomillada, es una evaluación subjetiva de la manifestación.

Otra importante área de análisis es el estudio de la elisión del agente y del auxiliar de las construcciones pasivas. Además de los procedimientos señalados por Gutiérrez, sobresale el hecho de que en La Extra muchos de los titulares se inclinan por la estructuración de la cláusula con elisión de agente, en cualquiera de las posibilidades sintácticas que brinda el español:

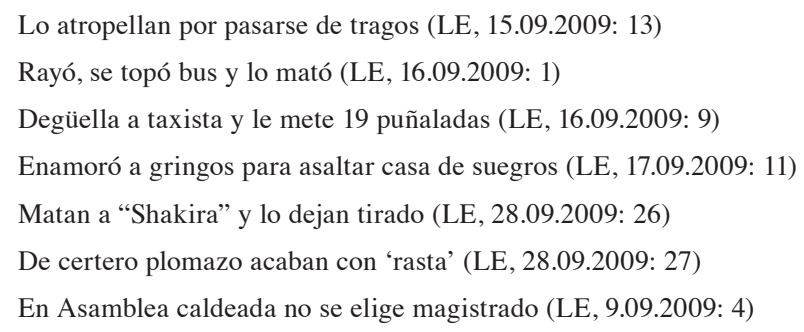

Aparecen construcciones pasivas o impersonales con se -“En Asamblea caldeada no se elige magistrado"-, sujeto tácito -"Rayó, se topó bus y lo mató"-, o impersonales gramaticales -"Lo atropellan por pasarse de tragos"-. Este tipo de enunciados permiten 
enfatizar la información que se quiere transmitir y eliminar la participación agentiva. Estos procedimientos resultan particularmente efectivos en las secciones de Sucesos, donde interesa destacar la acción, antes que el agente o el paciente, sobre todo si estos últimos no gozan de relevancia social.

También en La Nación, se elide el agente, junto con el auxiliar de las construcciones pasivas. Ambos procedimientos se utilizan simultáneamente:

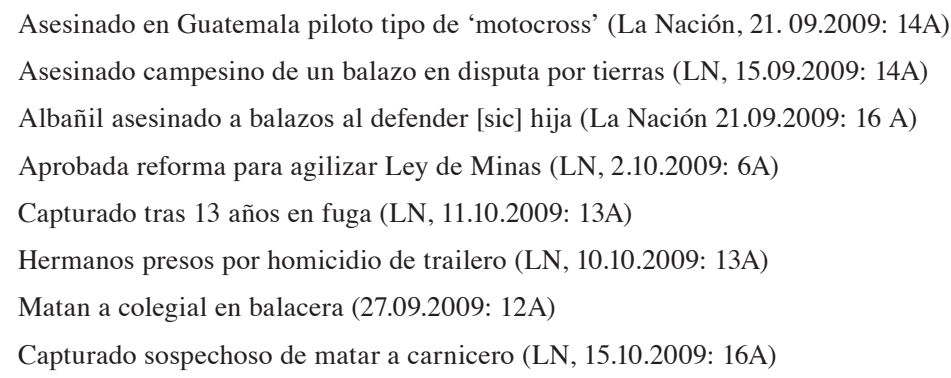

En todos estos casos, la utilización de participios pasados cumple la función de marcas residuales de oraciones pasivas implícitas (Urrutia Cárdenas 1981: 405). Por lo general, el protagonista de la noticia se describe desde el rol que asume en la acción descrita, mientras que el hipónimo se menciona en el cuerpo de la noticia (el nombre de los acusados, por ejemplo).

Las construcciones sintácticas en voz pasiva con elisión del verbo auxiliar y del agente permiten alcanzar concisión en el titular. Además, desde la función ideológica, y sobre todo en el ámbito de las acciones autoritarias de los Aparatos Represivos, tanto estatales como privados (en el caso de desalojos, golpes a manifestantes), interesa la omisión de la agentividad.

Con la elisión del agente en la sección de sucesos, las consecuencias de las acciones no son contractuales, sino que recaen sólo en una de las partes: la víctima. El discurso periodístico, centrado en representar la ausencia de orden (en destacar la omnipresencia del desorden, del caos), omite en el 'estrecho' espacio de los titulares al victimario para destacar, por contrapartida, a la víctima. Y en el marco de la búsqueda de concisión, el enunciador presupone que el lector inferirá la identidad, por lo menos genérica, del agente de la acción: los asesinatos son producidos por delincuentes, las capturas de delincuentes son realizadas por la policía.

Motivado por la economía del lenguaje de los titulares, muchos de estos últimos prescinden de los artículos determinados e indeterminados, como ocurre en los titulares aseverativos de La Nación: "Jueza adelantó tres días audiencia que liberó a policías" (LN, 15.09.2009: 1A), en lugar de "Una jueza adelantó tres días una audiencia que liberó a policías". Se procede a la eliminación de aquellas categorías prescindibles en el titular en términos de comprensión del enunciado por parte del lector. También se suele prescindir, aunque en menor medida, de verbos, sustantivos y preposiciones: se utiliza "Arias advierte sobre grupos extremistas en el país" (LN, 15.09.2009: 8A), en lugar de "Arias advierte sobre la presencia de sobre grupos extremistas en el país". Se usa "Muelleros insisten en asamblea para votar concesión" (LN, 30.09.2009: 7A), en lugar de "Muelleros insisten en ir a asamblea para votar concesión". Se emplea "Incofer impulsa plan para anillo de trenes urbanos" (15.09.2009: 1A), mientras que, para referirse al mismo referente, en la página 4A, el titular es el siguiente: "Incofer impulsa plan para instalar anillo de trenes urbanos" (15.09.2009: 4A). Por su parte, en "Mueren cuatro por operativo en favela" (17. 09.2009: 21 A), se omite la palabra 'personas', mientras que en "Cartago da primer paso para reactivar tren hacia San José" (15.09.2009: 5A), 
se elide "La municipalidad de Cartago". Cuando se prescinde del verbo, se llega al enunciado nominal: "Dos muertos en Metro de México por balacera" (LN,19.09.2009: 24A).

El empleo de tiempo verbal del presente del indicativo tiene muchas implicaciones semánticas. Cabe destacar que en La Nación, los titulares, en su mayoría, aparecen en el tiempo presente simple de indicativo, aunque los acontecimientos que representan hayan ocurrido en un pasado más o menos cercano. El determinante que incide en la práctica de este procedimiento estilístico es el valor-noticia de la actualidad. Podría considerarse en principio que el uso del presente de indicativo en los titulares se puede incorporar en la semántica del llamado presente histórico, orientado a incentivar que el lector 'visualice' el suceso como ocurrido ante su presencia.

Funciones distintas le asigna Alcoba Rueda (1983), quien además de considerar el presente de los titulares como no deíctico, es decir, como no indicador del momento temporal de la situación comunicativa o acontecimiento que relata, le asigna una función anafórica en relación con las coordenadas espaciotemporales utilizadas en la enunciación o relato del acontecimiento en el cuerpo de la noticia. En este último punto, el sentido temporal del presente del titular desarrolla relaciones de identidad semántica con el tiempo usado en el relato del acontecimiento. Es decir, si en el titular se dice "Político X rechaza la subida de impuestos" y en el cuerpo de la noticia se dice "Político $X$ ha rechazado o rechazó la subida de impuestos", el sentido temporal del presente del titular debe entenderse en relación anafórica con el tiempo utilizado en el cuerpo de la noticia.

Esta preferencia por el uso del presente simple de indicativo fue también estudiada y documentada por Francescutti (2009: 245), quien afirma que en la prensa española actual, dicho tiempo verbal se ha convertido en un dogma estilístico, cuyo desarrollo, -en el cuerpo de la noticia-, aparecerá en presente simple indicativo. Este uso se justifica a partir de la presión que ejerce la inmediatez televisiva y radiofónica en tanto se exige que los medios de comunicación estén presentes en el momento preciso en que ocurre la noticia; además "el presente simple hace gala de una multifuncionalidad que presta un atractivo adicional, pues vale tanto para infundir actualidad a los hechos pasados [...] como a acontecimientos futuros" (Francescutti 2009: 252).

Sorprende en La Nación, en todo caso, la abundancia relativa de titulares en futuro imperfecto, lo que demuestra la importancia que tiene la futura agenda institucional de actividades y planes, a corto y mediano plazo, en el temario de los periódicos: “Grecia tendrá hoy charla sobre esferas" (LN, 30.09.2009: 15A).

Contra lo que podría esperarse, el uso del pronombre de primera persona plural y la consecuente incorporación de la subjetividad aparece ocasionalmente en la titulación, sobre todo de la sección deportiva. Tanto en La Nación como en La Extra, la incorporación del nosotros inclusivo (todos los costarricenses), y del proceso de la enunciación, frente al nivel del enunciado, típico de los titulares y del lenguaje periodístico, aparece en las victorias de la Selección Mayor de Fútbol Masculino y de la Selección Sub-20:

Cuidado nos sacan las 'canguro' (LE, 30.09.2009: 20)

Deliramos con la Juvenil y la Mayor nos hace soñar (LN, 11.10.2009: 1A)

Se nos fue boleto a Sudáfrica en los últimos 20 segundos (LN, 15.10.2009: 1A)

En el deporte nacional, el periodista pierde la 'objetividad' discursiva, que en otros contextos trata de mantener, y manifiesta abiertamente su apoyo a un grupo en particular; 
en este caso, la selección de fútbol. Este fenómeno es válido en tanto el diario tematiza la realidad costarricense y manifiesta su lealtad a la nación. De hecho, en el caso de La Nación, desde su misma denominación se arroga el derecho de representar a todos los ciudadanos costarricenses, de ser su vocero, de materializar a la opinión pública costarricense.

Un excepcional caso de enunciado emotivo, totalmente alejado de las prescripciones para los titulares, que norman su carácter informativo, se encuentra en el titular sobre el empate de la selección de fútbol con EE.UU: “¡Demasiado cruel!” (LN, 15.10.2009: 36A) es un acto de habla cien por ciento expresivo (exclamación retórica, comparación, evaluación). Un caso similar es: “Cartago tuvo para más, pero ¡qué mala puntería!” (LN, 20.09.2009: 42A).

Por otra parte, el discurso periodístico se adapta a las variantes dialectales costarricenses y/o latinoamericanas. En Costa Rica esto se presenta en La Extra:

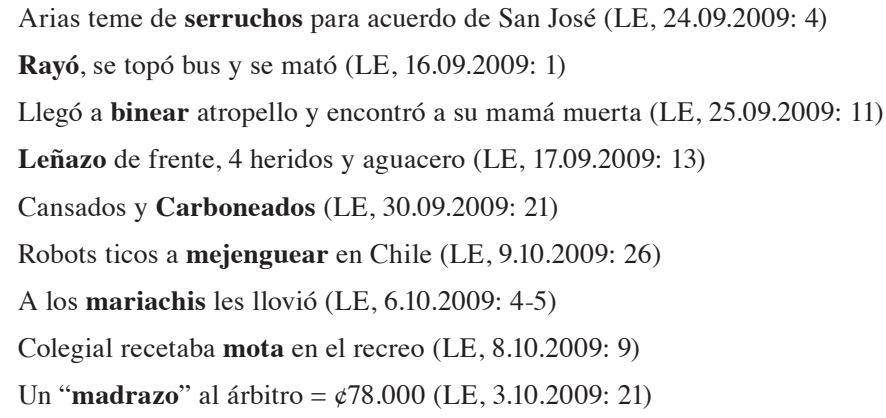

Nótese que en los ejemplos anteriores aparecen rubros léxicos que son de uso bastante frecuente a nivel nacional, pero que también podrían estar presentes en otros dialectos latinoamericanos. Palabras como "mota", "madrazo" o "leñazo" permiten al diario inscribirse dentro de un registro informal vinculado con los sectores populares. Otros términos como carbonear, binear, o mejenga aparecen en el Nuevo Diccionario de Costarriqueñismos de Quesada Pacheco y su uso permite infiltrar al producto periodístico como parte de la idiosincrasia costarricense. Esto no sucede en La Nación.

Por otra parte, La Extra muestra como característica particular el uso de los apodos de los individuos involucrados en la noticia, lo cual da un matiz al periodista como testigo presencial y allegado al evento:

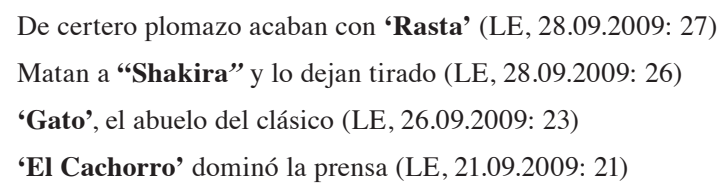

Un procedimiento novedoso registrado en La Nación es la incorporación de convenciones genéricas literarias en la redacción de los títulos. El 'érase una vez', procedimiento genérico del cuento, se utiliza en la publicación de una obra no publicada de Carmen Lyra: "Había una vez...un inédito de Carmen Lyra" (en cursiva en el original) (LN, 11.10.2009: 28 Áncora).

Con algunos titulares, se quiere promover el suspenso en el lector, para que prosiga la lectura en el cuerpo de la noticia. Esto sucede, más que todo, en la sección de Espectáculos. Es el caso de "Show pondrá a prueba la masculinidad" (LN, 15.09.2009: 20Viva), sobre un monólogo teatral. 


\section{Conclusiones}

Prácticamente, la totalidad de los titulares de La Nación son enunciados verbales en presente (son escasísimos los enunciados nominales). Esta situación se encuentra en consonancia con la práctica de la titulación de los periódicos de referencia dominante (periódicos que son referencia para otros medios de comunicación y para la sociedad), incluso de aquellos publicados en otros idiomas ${ }^{2}$.

En la mayor parte de los casos, ambos periódicos introducen sus titulares por medio de aseveraciones, de enunciados asertivos. Dicho procedimiento permite cumplir con el ideal de presentar una noticia “objetiva”, en la que idealmente se representaría el acontecimiento sin que medien valoraciones entre ésta última y el lector.

Cuando se incorpora el juego de voces, es decir, el discurso reproducido de las fuentes, tanto La Nación como La Extra utilizan el estilo directo, aunque en escasas ocasiones. El estilo indirecto, sin ser relevante su aparición, es más característico de La Nación que de La Extra. A diferencia de otros países, como España, la cita reproducida aparece escasamente en $L a$ Nación, tanto las citas directas sin sujeto (reducidas a la sección deportiva), ya sean bimembres, con verba dicendi o con palabra entrecomillada, como en el caso de la cita indirecta. No debe confundirse este último procedimiento con aquellos casos en los que dentro de un titular asertivo o aseverativo se puede rastrear la voz del periodista, quien circunscribe su voz mediante la utilización de comillas.

Los presupuestos se encuentran detrás de muchos de los fenómenos lingüísticos analizados, a su vez motivados por la necesidad de la concisión. Por ejemplo, la siglación se constituye como un mecanismo altamente utilizado en el que las presuposiciones del enunciador permiten la concisión informativa de muchos titulares. Otras modalidades de presuposiciones consisten en mencionar el nombre de una empresa sin brindar información respecto a ésta -caso de Sardimar, Calvo-, o bien se usa sólo el nombre o el apellido de personajes conocidos en el ámbito nacional Ottón, Laura-, que no requieren ningún otro enunciado introductorio. Si la persona no es conocida, entonces se recurre a uno de los siguientes procedimientos: uno, llamarlo por su rol social (vecino, cliente, espectador. .); dos, se puede elidir el agente, ya sea utilizando nominalización deverbal, las oraciones pasivas con se o las impersonales, o por sujeto elíptico; tres, en el caso de La Extra, se puede utilizar el apodo de uno de los involucrados en la noticia, sea el agente, el paciente o testigo, siempre y cuando el apodo sea suficientemente llamativo y original por sí mismo.

Susana Guerrero (2007) afirma que el discurso periodístico español busca insertar dentro de sus enunciados la creatividad, como método para atraer al lector. El presente estudio quiso comprobar si a nivel nacional sucede lo mismo. Los recursos lingüísticos utilizados varían de país en país. Así, mientras que Guerrero (2007: 114), en el caso español, considera que la prefijación es de gran incidencia e importancia en la prensa, a nivel costarricense no resultó relevante, pues los escasos ejemplos encontrados provenían de un uso convencional del lenguaje -como en vicepresidente- y no con el propósito de crear un nuevo léxico, de carácter imaginativo -como en anti-botellón-.

En el ámbito de la sufijación, se utilizaron, más que todo, sufijos generadores de profesiones y gentilicios, así como el diminutivo ponderativo-ito. El sufijo más utilizado en $L a$ Extra es -azo, que se reviste de una variedad de significados y funciones (sobre todo la enfática), mientras que en La Nación no se reportaron casos en los que se registrara su aparición.

En cuanto a otros procedimientos de sufijación, en la prensa nacional la nominalización deverbal, como recurso que permite elidir al agente al mismo tiempo que brinda economía 
lingüística, es un procedimiento escaso. La nominalización, tanto la deverbal como la deadjetival, que 'representa' la realidad social desde lo estático ("fraude" en lugar de "X defrauda"), se usa más en La Extra que en La Nación, sin que esto implique que goce de preferencia en el primer periódico. Los prefijos no resultaron ser productivos en tanto generadores de nuevos vocablos ni en La Extra ni en La Nación. Dicha práctica dista de la existente en otros países, como México (Nadal Palazón 2008) o España (Casado Velarde 1978).

En principio, por lo que respecta a la elisión del agente, procedimiento investigado por Van Dijk (1997) y por Sandoval (2002) junto con la nominalización, operan intereses ideológicos. El análisis crítico del discurso considera la elisión del agente desde motivaciones ideológicas, como en el caso "Precaristas desalojados" donde se omite "por la policía". En todo caso, también cabe reflexionar sobre la necesidad que tienen las empresas periodísticas de alcanzar concisión en el titular. Esto motivaría también la exclusión del agente, convertido en presupuesto, en "Transeúnte atracado", donde se elude "por un delincuente". Con el objetivo puesto en la búsqueda de la concisión, el periódico presupone que el lector ya conoce los tipos de agentes sociales que cumplen estas acciones y los omite.

La composición se utilizó, asimismo, en muy pocos casos en ambos diarios. Cuando aparece, permite condensar en una palabra el sentido, más que todo metafórico, de la noticia. Mediante estos procedimientos morfológicos (prefijación, sufijación, composición), que conducen a la creación de neologismos, se pretende llamar la atención del lector al caracterizar novedosamente la 'realidad social'.

Tanto en La Nación como en La Extra, frente al escaso uso de figuras retóricas de carácter sintáctico (figuras de posición, omisión, reducción o amplificación), se hace uso regular de los tropos o figuras retóricas de carácter semántico. El uso de las metáforas, por ejemplo, es bastante frecuente. Destaca su uso, siempre creativo, en la sección deportiva. Son relevantes en la construcción de titulares concisos, por cuanto una de las funciones de la metáfora es la condensación de sentido.

Por último, los neologismos o vocablos procedentes del inglés no son productivos ni en La Nación ni en La Extra. Esto último diferencia la titulación periodística del discurso publicitario.

En el caso de La Extra, las expresiones hechas y el uso de términos propios del registro informal sea costarricense - como binear o carbonear- o bien latinoamericano como mota- es muy frecuente y permite inscribir al periódico en el ámbito sensacionalista, pues según Sunkel (2002: 109), dicho campo profesional periodístico se destaca porque "las noticias son presentadas en un lenguaje coloquial y cotidiano, el que es especialmente usado en los sectores populares". La Extra utiliza el léxico de las clases populares como un recurso edificador de familiaridad y cercanía con el lector (no en vano la prensa se declara vocera de los costarricenses). El uso del registro formal/informal supone una influencia recíproca entre el grupo de hablantes y la prensa. Para Carla Jara (2006: 144), el hablante "trata de compaginar modelos expertos a los que les atribuye autoridad en la lengua española: en primer lugar, La Real Academia Española, en segundo lugar, columnistas de la prensa nacional". Es decir, como modelo experto, el público reviste al periódico de autoridad. Según los modelos culturales establecidos por la autora, aquellos hablantes cuya valoración de la lengua sea negativa o se sitúe más cerca de una lealtad crítica de su variante dialectal, hallarán en el periódico $L a$ Nación una fuente divulgadora de una variante estándar legitimada. Por su parte, aquellos cuyas valoraciones tiendan más hacia la lealtad lingüística y las variaciones dialectales, se 
identificarán con el léxico y expresiones utilizadas por La Extra. Además, el uso del léxico de las clases populares en este diario demuestra la influencia que posee la forma de hablar de los costarricenses en la construcción de la noticia y su inserción dentro de la realidad de la comunidad lingüística a la que va dirigido.

En La Nación, y un poco menos en La Extra, son comunes las construcciones sintácticas en voz pasiva con elisión del verbo auxiliar y del agente. Es uno de los escasos procedimientos que singulariza dicho periódico frente al resto de los diarios nacionales y extranjeros. El motivo del uso del participio pasado como marca residual de una oración pasiva es la economía del lenguaje del titular y el manejo de las presuposiciones del enunciador (La Nación) sobre el nivel de conocimiento de los destinatarios.

Los únicos casos de titulación emotiva en ambos periódicos aparecen en la sección deportiva. Se acepta implícitamente la identificación de la empresa periodística hacia una entidad, la Selección Nacional, que representa los intereses de Costa Rica como nación, más allá de los políticos partidistas. En acciones que representan a Costa Rica, y que activan la identificación de todos los costarricenses, la retórica de la objetividad se deja de lado.

A partir de esta investigación, se pueden proponer las siguientes recomendaciones, desde los siguientes enfoques, como temas para futuros estudios: a. Comparar los procedimientos lingüísticos y el léxico de dos diarios sensacionalistas costarricenses (por ejemplo, La Extra y La Teja); b. Comparar los procedimientos lingüísticos utilizados en los titulares de La Nación y los elaborados por otros diarios de referencia dominante extranjeros (como son El País, en España, o La Nación, de Argentina); c. Comparar los procedimientos lingüísticos de las versiones impresas de los diarios nacionales y las versiones digitales; d. Comparar los procedimientos lingüísticos de los titulares de los diarios frente a los utilizados por las revistas; e. Comparar los procedimientos lingüísticos de los titulares de los diarios frente a los utilizados por los sumarios en los tele-informativos; f. Una vez comprobada la 'alta' presencia de enunciados metafóricos y enunciativos en los titulares deportivos de La Nación, se pueden comparar estos últimos titulares con los titulares deportivos de los diarios sensacionalistas del país, con el propósito de establecer similitudes y diferencias; g. Explorar la alta incidencia de enunciados nominales en el periodismo costarricense, una vez que González Rodríguez ha analizado su relevancia en el periodismo sensacionalista británico; h. También se pueden explorar las relaciones entre el titular propiamente dicho, la volanta (el antetítulo) y la bajada. Como descripción inicial de un campo de relaciones muy complejo, podemos decir que ocasionalmente la volante ofrece complementos circunstanciales (de lugar, por ejemplo: 'En Cartago') que el titular no incorpora; y i. Por último, se pueden explorar distintas relaciones entre el titular y el cuerpo de la noticia: uno, los mecanismos para condensar el sentido de la noticia (es decir, analizar el titular como una macroestructura, desde los planteamientos de Van Dijk).

\section{Notas}

1. Recuérdese que en los inicios de la gramática generativa, las nominalizaciones se entendían como resultado de transformaciones (Nadal Palazón 2008: 179).

2. González Rodríguez (2002: 137) establece la siguiente conclusión en la prensa británica: “todos los titulares que conforman la muestra de las publicaciones de formato sabana (up-market) se incluyen en la clasificación de titulares verbales. [...] Por contraste, en las publicaciones tabloides más populares (down-market) se detecta un gran número de titulares carentes de elemento verbal". 


\section{Bibliografía}

Adam, Jean-Michel y Marc Bonhomme. 2000. La argumentación publicitaria. Retórica del elogio y de la persuasión. Madrid: Cátedra.

Alboca, Santiago. 1983. "El presente de los titulares de prensa: no deíctico, pro-tiempo anafórico". Anàlisi. (7-8): 107-121.

Alcoba, Santiago (coord.). 1999. La oralización. Barcelona: Editorial Ariel.

Almeda Pérez, Ramón. 1999. Procedimientos de formación de palabras en español. Madrid: Ariel.

Barthes, Roland. 1986. Lo obvio y lo obtuso. Imágenes, gestos, voces. Barcelona: Editorial Paidós.

Brown, G. y Yule, G. 1983. Discourse Analysis. Cambridge: Cambridge University Press.

Calsamiglia Blancafort, Helena y Amparo Tusón Valls. 1999. Las cosas del decir. Manual de Análisis del discurso. Barcelona: Editorial Ariel.

Casado Velarde, Manuel. 1978. "La transformación nominal, un rasgo de estilo de la lengua periodística”. Cuadernos de investigación filológica. (4): 101-112.

Cervantes, Miguel de. 2001. El ingenioso hidalgo Don Quijote de la Mancha. España: Editorial Óptima.

Cuvardic García, Dorde. 2004. “La metáfora en el discurso político”. Reflexiones. 83(2): 61-72.

Escribano, Asunción. 2007. "El discurso reproducido en las informaciones electorales". Anàlisi. (35): 65-82.

Francescutti, Luis Pablo. 2009. "El tiempo de los titulares. Un análisis verbal de la titulación en la prensa española durante el periodo 1980/2005”. Estudios sobre el Mensaje Periodístico. (15): 243-259.

González Rodríguez, María José. 2002. La incidencia de la dimensión contextual en la producción del título periodístico". Atlantis. 129-148.

Guerrero Salazar, Susana. 2007. La creatividad en el lenguaje periodístico. Madrid: Cátedra.

Hall, Stuart. 1980. “Encoding/decoding”. En: Hall y otros (comps.), 128-38.

Hall, Stuart y otros (comps.). 1980. Culture, Media, Language. Londres: Hutchinson. 
Hernando Cuadrado, Luis Alberto. 2000. Discurso periodístico. Madrid: Editorial Verbum.

Jara, Carla. 2006. El español de Costa Rica según los ticos. San José: Editorial de la Universidad de Costa Rica.

López García, Ángel. 1996. Escritura e información. La estructura del lenguaje periodístico. Madrid: Cátedra.

López Hidalgo, Antonio. 2001. El titular: manual de titulación periodística. Sevilla: Comunicación Social.

Martini, Stella. 2000. Periodismo, noticia y noticiabilidad. Bogotá: Editorial Norma.

Morales, H. López. 1994. Métodos de Investigación Lingüística. Salamanca: Ediciones Colegio de España.

Nadal Palazón, Juan. 2008. "Verdades a medias: la nominalización deverbal en los titulares periodísticos”. Comunicación y Sociedad. (9): 175-185.

Quesada Pacheco, Miguel Ángel. 2007. Nuevo Diccionario de Costarriqueñismos. Cartago: Editorial Tecnológica Costarricense.

Ruiz Gurillo, Leonor. 2000. "Las metáforas de un día en los medios de comunicación españoles”. E.L.U.A. (14): 199-215.

Sandoval García, Carlos. 2002. Otros amenazantes. Los nicaragüenses y la formación de identidades nacionales en Costa Rica. San José: Editorial de la Universidad de Cota Rica.

Sunkel, Guillermo. 2002. La prensa sensacionalista y los sectores populares. Bogotá: Editorial Norma.

Van Dijk, Teun A. 1990. La noticia como discurso. Comprensión, estructura y producción de la información. Barcelona: Paidós.

1997. Racismo y análisis crítico de los medios. Barcelona: Editorial Paidós.

2000. Ideología. Una aproximación multidisciplinaria. Barcelona: Editorial Gedisa.

2003. Racismo y discurso de las élites. Barcelona: Editorial Gedisa. 